73rd Conference of the Italian Thermal Machines Engineering Association (ATI 2018), 12-14 September 2018, Pisa, Italy

\title{
Comparison of 0D and 3D Hydraulic Models for Axial Piston Pumps
}

\author{
Alessandro Corvaglia ${ }^{\mathrm{a},}$, Massimo Rundo ${ }^{\mathrm{a},{ }^{*}}$ \\ aPolitecnico di Torino, Dipartimento Energia"Galileo Ferraris", C.so Duca degli Abruzzi 24, 10129, Torino
}

\begin{abstract}
In this the paper, a comparison between a $0 \mathrm{D}$ and a 3D model for the simulation of an axial piston pump is presented. The lumped parameter approach implements a detailed mathematical model developed in the Amesim ${ }^{\mathbb{B}}$ environment for the evaluation of the geometric features of the variable chambers. The commercial tool PumpLinx ${ }^{\circledR}$ has been used for the 3D computational fluid dynamics model. The aim is to assess the capability of the $0 \mathrm{D}$ model in predicting the main quantities and to evaluate the use of the three-dimensional analysis for fine tuning purposes.

The comparison has been performed in conditions of fixed displacement and constant speed. A good agreement was found in the evaluation of the flow ripple and of the chamber pressure history.
\end{abstract}

(c) 2018 The Authors. Published by Elsevier Ltd.

This is an open access article under the CC BY-NC-ND license (https://creativecommons.org/licenses/by-nc-nd/4.0/)

Selection and peer-review under responsibility of the scientific committee of the 73rd Conference of the Italian Thermal Machines

Engineering Association (ATI 2018).

Keywords: axial piston pump; lumped parameter model; CFD

\footnotetext{
* Corresponding author. Tel.: +39-011-090-4406; fax: +39-011-090-4599.

E-mail address: massimo.rundo@polito.it
} 


\section{Introduction}

In the last years, different simulation approaches have been presented for studying positive displacement machines [1]. The most common method is represented by the lumped parameter model, where it is assumed that in each control volume the fluid has homogeneous properties. Its main merit is the fast computational time, even if some physical phenomena must be inevitably simplified. However it is possible to describe geometrically the unit with a very high accuracy, also with the aim of CAD tools [2].

\begin{tabular}{|ll|ll|}
\hline \multicolumn{2}{|l|}{ Nomenclature } & & \\
$b$ & gap width & $V_{0}$ & clow area \\
$C_{d}$ & discharge coefficient & $\alpha$ & swashplate tilt angle \\
$D_{p}$ & piston diameter & $\beta$ & bulk modulus \\
$h$ & gap height & $\rho$ & fluid density \\
$l$ & gap length & $\varphi$ & shaft angle \\
$p$ & pressure & $\mu$ & dynamic viscosity \\
$R_{m}$ & circumference radius of piston axes & $\omega$ & angular velocity \\
$Q$ & volumetric flow rate & \\
\hline
\end{tabular}

The three-dimensional CFD approach is the most advanced method, but the CPU times are orders of magnitude higher. PumpLinx is a very popular software specific for the simulation of pumps. Just recent examples are the works of Frosina et Al. on balanced rotor vane pumps [3] and on external gear pumps [4]. However, it is very complicated with 3D CFD models to implement some features, such as the variable clearances or the elastic deformations of the bodies. For these specific aspects, different ways can be followed. With reference to external gear machines, Borghi and Zardin [5] used a commercial FEM software for evaluating iteratively the stiffness matrix of the balance plates and the pressure field in the gap with 2D CFD simulations. A further step is to calculate at the same time both the deformation and the instantaneous position of a mechanical part as function of the current pressure field [6]. Nevertheless the 3D CFD simulations can be efficiently used as a tool for optimizing and tuning a 0D model, along with other FEM software packages. Examples of applications can be found in the references [7] for crescent pumps, [8] for gerotor pumps and [9] for variable displacement vane pumps. Overall, the proper combination of CFD and OD simulations represents a time-efficient tool that can be utilized for assessing the interaction between the pump and a fluid power circuit.

With specific reference to the modelling of axial piston pumps, a significant contribution was provided by research works performed at the Purdue University with dedicated proprietary tools [10]. An integration between a 0D hydraulic model and a multi-body tool was also developed at the Politecnico di Torino by Roccatello et Al. [11]. Other authors [12] performed a similar co-simulation for optimizing the pump and made a CFD analysis of the new geometry. Numerous papers deal with very specific aspects of the pump, such as the modelling of the fluid [13], the CFD simulation of the slippers [14], the evaluation of the friction force within the cylinder bores [15] and so on. However very detailed models are not suitable for system-level studies, such as in hydrostatic transmissions [16], due to the complexity of the circuit. A possible solution is to simulate the unit by interpolation of look-up tables, which in general can be obtained by experimental measurements or by a more or less complex model. This approach becomes mandatory if the model is used for a real-time simulation [17]. Hence, regardless of the specific application, it is becoming more and more important to contrast $0 \mathrm{D}$ and 3D models in order to understand the type of phenomena that can be correctly simulated. For instance, an aspect that must be reproduced with a very good accuracy is the transition of the chambers from the inlet to the outlet volumes and vice versa, above all with unconventional port plates [18]. A recent example of comparison between a lumped parameter and a PumpLinx model of a pump is described in the paper of Pellegri et Al. [19], for the case of a gerotor unit. A similar comparison is not still present in the open literature for axial piston pumps.

In the current paper a $0 \mathrm{D}$ model of a swash plate piston pump developed in the Amesim environment is contrasted with a 3D PumpLinx model in terms of flow rates and chamber pressure history. The aim is to evaluate if the simplifications adopted in a lumped parameter approach have a significant influence on the results. 
The unit used as reference is a Casappa LVP48 swashplate axial piston pump with a displacement of $45.5 \mathrm{cc} / \mathrm{rev}$ and maximum operating pressure of 350 bar. In Figure 1a a section view of the pump is shown. The pump has 9 pistons provided with hydrostatic slippers sliding on the flat surface of the swashplate. The tilt angle of the swashplate defines the pump displacement, which can be modified by means of two hydraulic actuators and one or more pilot valves depending on the type of control. The details of the displacement control are not reported in this paper, since the study was performed at fixed tilt angle. A view of the port plate, provided with triangular silencing grooves is shown in Fig 1b.
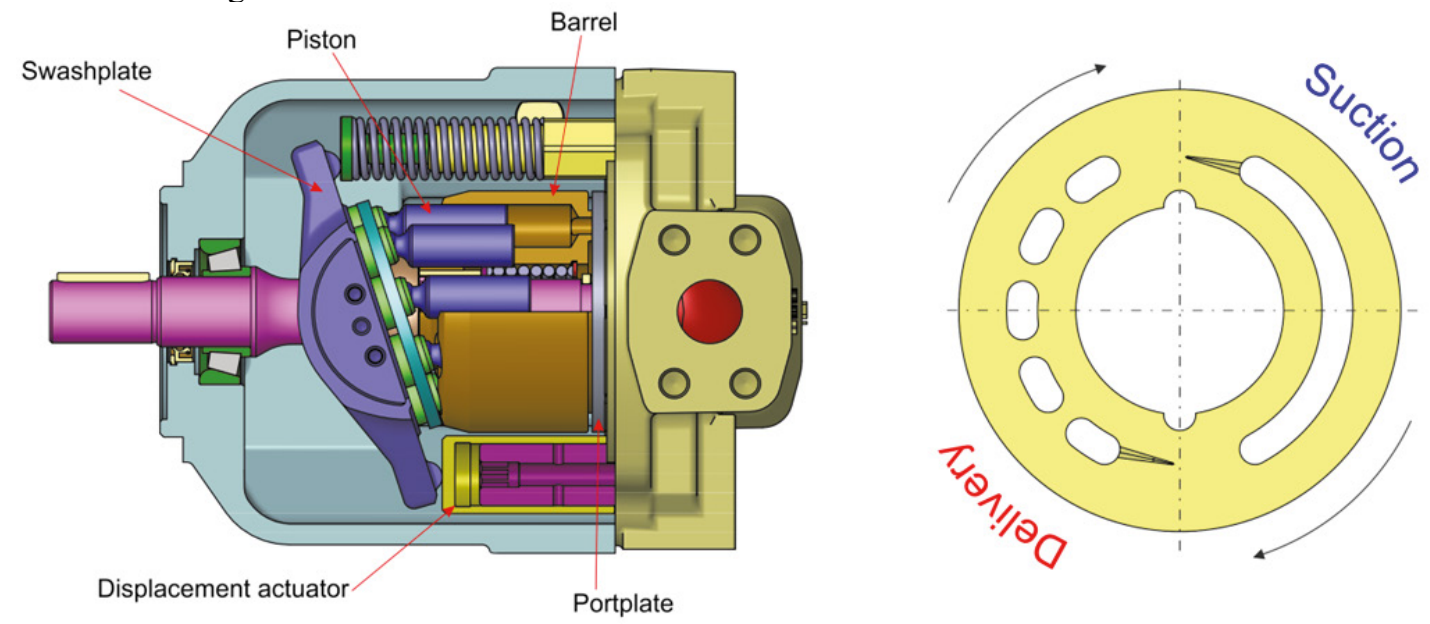

Fig 1. (a) section view of the axial piston pump; (b) detail of the port plate.

\section{Lumped parameter model}

\subsection{Basic equations}

The fluid domain is divided in control volumes, to which the mass conservation in isothermal conditions is applied in order to calculate the pressure $p$ :

$$
\frac{d p}{d t}=\frac{\beta}{V}\left(\sum Q_{i}-\omega \frac{d V}{d \varphi}\right)
$$

being $Q_{i}$ the $i$-th flow rate (positive if ingoing). The control volumes are associated to the variable chambers and to fixed capacities representing the volume of the pipes. The volume and the derivative of a chamber are calculated as function of the shaft angle and of the tilt angle $\alpha$ of the swashplate:

$$
\begin{aligned}
& V=\frac{\pi D_{p}^{2}}{4} R_{m} \tan \alpha(1-\cos \varphi)+V_{0} \\
& \frac{d V}{d \varphi}=\frac{\pi D_{p}^{2}}{4} R_{m} \tan \alpha \cdot \sin \varphi
\end{aligned}
$$

The control volumes are connected by hydraulic resistances, representing the flow areas $S$ in the port plate and the leakage passageways. For the former, the Eq. (4) for flow in turbulent regime condition is used for calculating the flow rate as function of the pressure drop $\Delta p$ :

$$
Q=C_{d} S \sqrt{\frac{2 \Delta p}{\rho}}
$$


For the latter, the Eq. (5) for laminar flow through a constant-height rectangular gap with width $b$, height $h$ and length $l$ is applied:

$$
Q=\frac{b h^{3}}{12 \mu l} \Delta p
$$

The flow area $S$ is calculated analytically as the intersection between the profile of the kidney port and the contour of the hole on the cylinder block. Through the silencing grooves, it is calculated as the minimum between the frontal and cross sectional area of the groove itself.

\subsection{Amesim implementation}

The aforementioned mathematical model has been implemented in the Amesim environment. Most submodels have been developed in-house using a vector approach, so that all components of the same type (chambers, restrictors and gaps) are simulated by a single submodel, in which the geometric quantities of the different chambers are simply shifted by the angular pitch. The advantages are the simplification of the layout and the possibility to make the number of chambers a parameter. The sketch of the complete model is presented in Fig. 2. The configuration shown includes the absolute pressure limiter (A), the Load Sensing control (B) and the torque limiter (C).

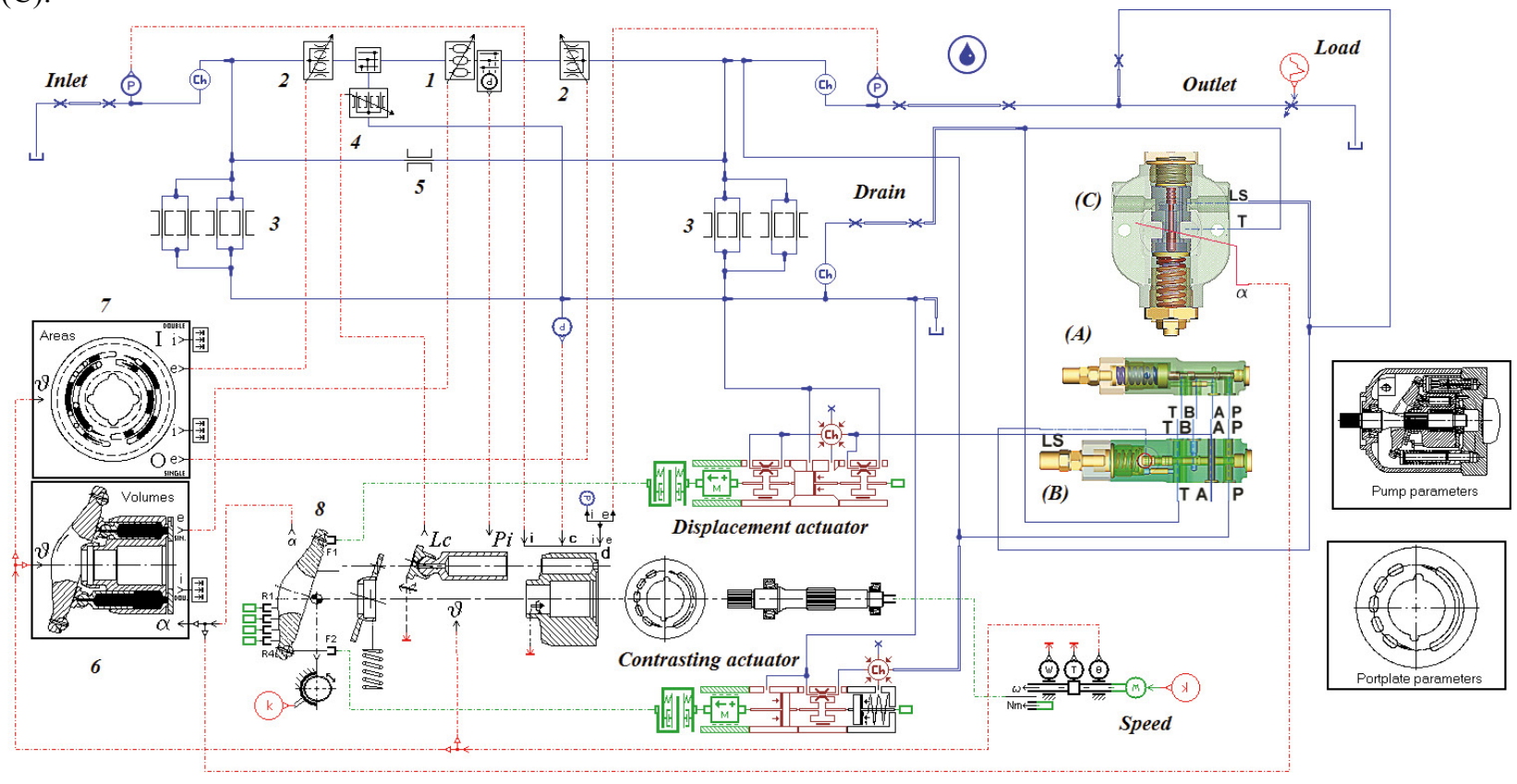

Fig. 2. complete model of the pump in the Amesim environment.

The component 1 simulates all chambers, connected to the inlet and outlet ports through the variable restrictors 2 simulating the port plate. The submodels 3 calculate the leakages on the two sides of the port plate in the radial direction, while the component 4 the leakage through the clearance between each piston and the respective bore in the barrel. Finally the submodel 5 calculates the cross-port leakage through the port plate.

The history of the volumes and of the derivatives is evaluated by the component 6 and supplied to the chambers 1. In a similar way, the flow areas are calculated by the element 7 . In the lower part of the circuit, the models for the evaluation of the forces and torques on the mechanical components are shown. In particular, the element 8 evaluates the dynamic equilibrium of the swashplate as function of the forces exerted by the actuators and by the pistons. 
The actuators are modelled using the Hydraulic Component Design library as well as the controls, which are represented by means of the "supercomponent" facility.

The model validation is reported in a previous paper [20] in terms of steady-state flow-pressure characteristics, while in the reference [21] a comparison between the simulated and the experimental pressure ripple and more details about the controls can be found. Depending on the type of study, also other phenomena could be taken into account. For instance, by means of a specific submodel (not shown in Fig. 2), it is possible to study the variation of the gap between the cylinder block and the port plate by means of a 2D simulation of the pressure field. Another very important feature that will be implemented in a future version of the model is the slipper dynamics. The analysis of the slipper-swashplate interface has been studied with different levels of details by many authors, for instance to determine the condition of instability [22] or more recently involving the thermo-elasto-hydrodynamic lubrication [23].

\section{CFD model}

The commercial software PumpLinx ${ }^{\circledR}$ was used for building the 3D model. It discretizes the governing equations with the finite volume method and allows managing moving grids through specific templates for piston pumps. The volume of fluid was extracted from the CAD geometry, then was divided in subdomains, converted in STL format and imported in PumpLinx. The model of the pump is shown in Fig. 3; the displacement control is not included, being the study performed at fixed tilt angle.

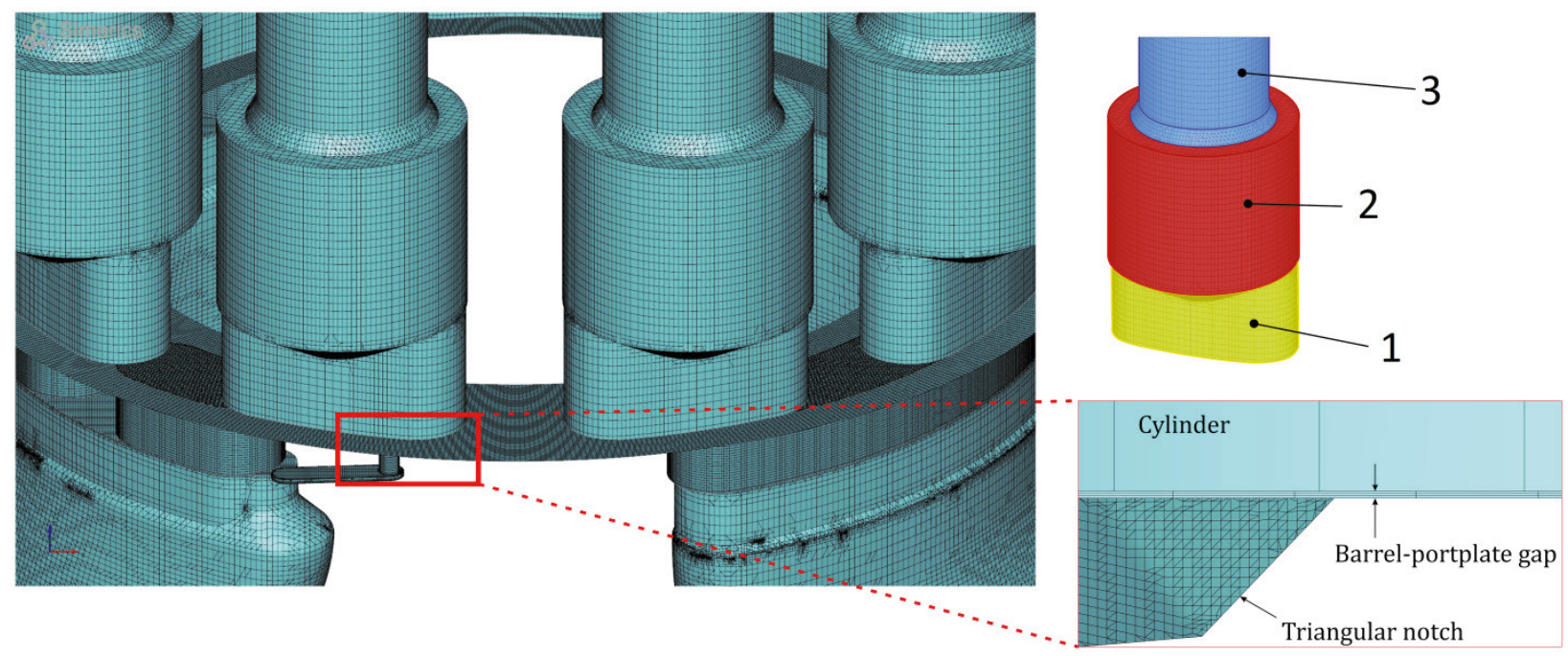

Fig. 3. model of the pump in PumpLinx with indication of three different regions in a piston and the detail of the mesh in a notch.

The cells belonging to the variable chambers rotate around the shaft axis. In particular the cells in the region 1 rotate rigidly, being anchored to the barrel, while the cells inside the hollow pistons (3) also translate along the cylinder axis. Finally the cells in the region 2 are also stretched in order to follow the movement of the piston. In the model, the leakage between the cylinder block and the port plate is simulated by means of an annular disc with three layers of cells (see the detail). Two additional passageways could be considered: the radial clearance between the piston and the bore and through the hydrostatic slippers, assuming a constant height of the gap. However, due to the simplified geometry of the gap with respect to the lumped parameter model, it has been preferred to not consider these last two leakages in this first study, due to the difficulty of comparison. The details about the equations used in the software and the management of the volume interfaces can be found in the reference [24].

A single-phase model of the working fluid is implemented, nevertheless it is able to manage the gas and vapor release [25], since it computes the variation of the mixture density as function of the local pressure. The fraction of 
air is calculated as function of the local pressure and of the equilibrium value given by the Henry's law. The separation and dissolution phenomena are considered instantaneous.

Some tests with the standard model k- $\varepsilon$ were performed, but it was found that the turbulence model has negligible influence on the results in this particular application.

The simulations were performed with an angular step of the shaft of $0.5^{\circ}$. As boundary conditions, the atmospheric pressure was imposed at the inlet port and on the lateral surfaces of the gap of the port plate, while a delivery pressure of 300 bar was set at the outlet. The working fluid has a kinematic viscosity of $28 \mathrm{cSt}$ and a density of 855 $\mathrm{kg} / \mathrm{m}^{3}$. An almost pure oil, with just $0.1 \%$ of total air, has been considered.

\section{Results and comparisons}

The mesh sensitivity analysis of the CFD model was performed by progressively increasing the number of cells in the interface between the barrel and the port plate, in particular in the silencing grooves. In fact this region is particularly critical for capturing the transition of a chamber from the low to the high pressure volumes and vice versa. In Fig. 4 the detail of the mean pressure in a chamber as function of the shaft angle is plotted for 5 different levels of refinement. In the legend, the CPU times expressed in hours per shaft revolution are also indicated. The simulations were performed on an eight-core Xeon HT processor at 3.4 GHz. The depressurization of the chamber is more sensitive to the number of cells. The next results have been obtained with a total number of 2.9 million cells, even if it is evident that about 1 million is largely enough.
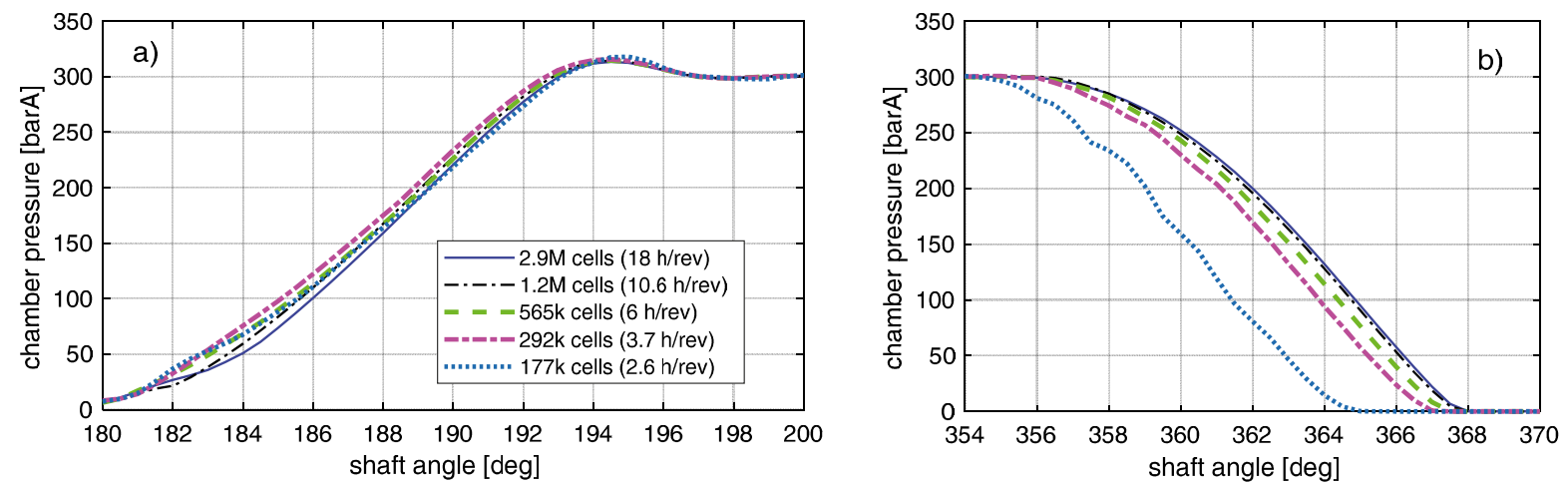

Fig. 4. (a) chamber pressure at the beginning and (b) at the end of the delivery phase with different numbers of cells at $1500 \mathrm{rpm}$.

The comparison with the lumped parameter model is shown in Fig. 5 in terms of chamber pressure (in PumpLinx it is the average value calculated on the entire chamber volume). The discharge coefficients used in the Eq. (4) have been left to the default value of 0.7 . With the $0 \mathrm{D}$ model the pressure is slightly higher at the beginning of the delivery phase, while the slope is the same with a small delay at the beginning of the suction phase. However, overall, the differences are quite negligible in spite of a significantly lower computational time, about 10 seconds per revolution.

A possible use of the CFD model is the tuning of the discharge coefficients to be used in the 0D model. It was found that for the beginning of the delivery phase, a coefficient of 0.7 already represents the best compromise for reproducing the pressure increase in Fig. $5 \mathrm{~b}$, while for the end of the delivery phase a better behavior is obtained with $C_{d}=0.8$, as shown in Fig. 5c. In Fig. 6 the flow ripple is shown; in PumpLinx it has been measured on the boundary interface where the outlet pressure of $300 \mathrm{bar}$ is imposed. The amplitude of the oscillation is slightly higher with the CFD, while the mean value is $63.55 \mathrm{~L} / \mathrm{min}$ against $63.44 \mathrm{~L} / \mathrm{min}$ calculated with Amesim. Also for the instantaneous flow rate, $C_{d}=0.7$ gives the best results. For sake of completeness, the flow rate calculated with PumpLinx with 1.2 million cells is $63.61 \mathrm{~L} / \mathrm{min}$. 

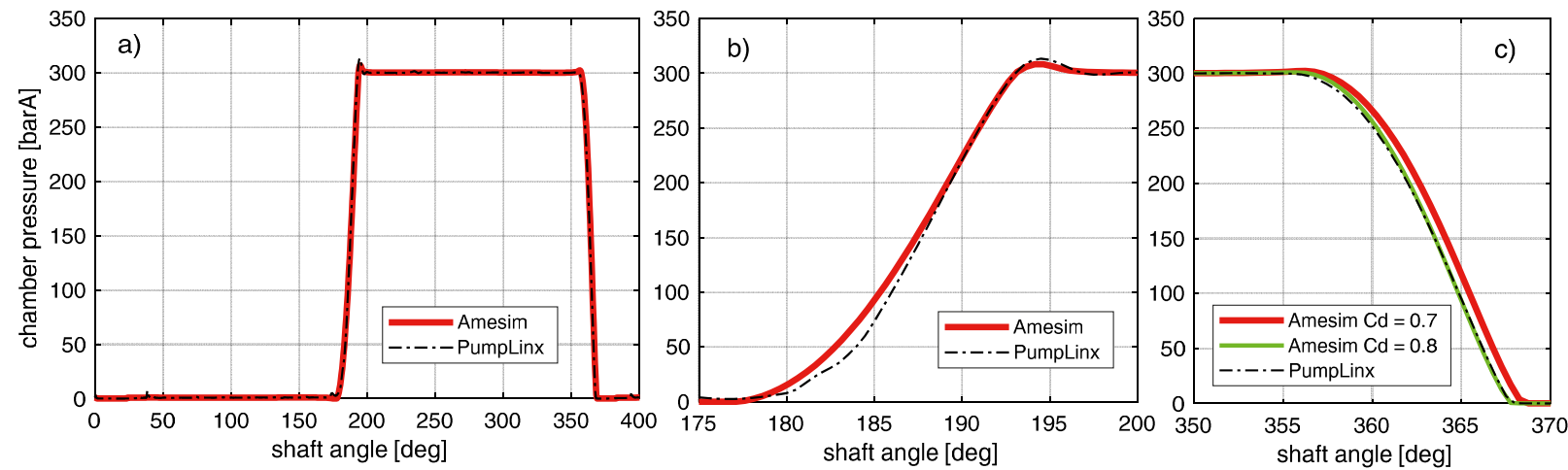

Fig. 5. (a) pressure in a chamber in a complete revolution of the shaft; (b) detail of the connection with delivery and (c) inlet volumes.

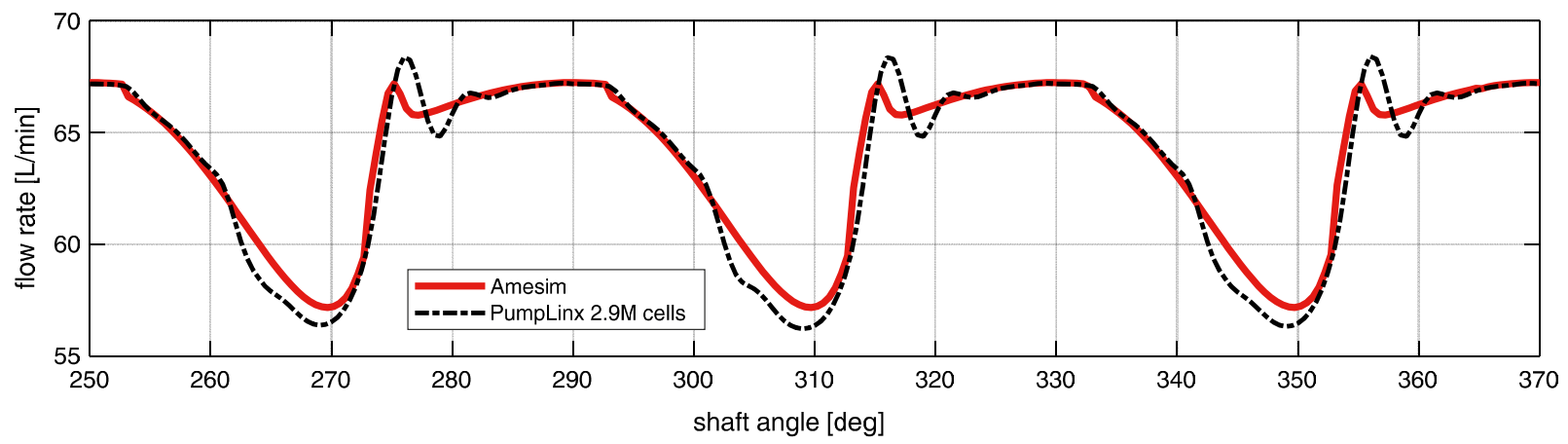

Fig. 6. simulated flow ripple with discharge coefficients equal to 0.7 .

\section{Conclusions}

In this paper, the comparison between two simulation approaches for studying an axial piston pump has been presented. The first method is based on a 0D proprietary library developed in the Amesim environment, the other one exploits the commercial software package PumpLinx. The 0D model can simulate the pump with different levels of detail and in particular also the interaction between the fluid and the dynamics of some components. These aspects cannot be reproduced easily in a CFD environment that, on the contrary, allows taking into account the nonhomogeneous pressure distribution in the control volumes and to evaluate with a higher accuracy the pressure drops in complex geometries. In order to compare the two approaches, the reference pump has been simulated at constant displacement with only the leakage on the port plate. As far as the comparison of the chamber pressure history and of the flow ripple is concerned, quite small differences have been found, without any specific tuning of the 0D models. This suggests that the $3 \mathrm{D}$ effects, in the analyzed operating condition, are not so important. Even better results can be achieved by tuning the discharge coefficients.

\section{Acknowledgements}

The present work was partially performed within research projects between Politecnico di Torino and Casappa $\mathrm{SpA}$. Authors acknowledge permission of publishing the present material. 


\section{References}

[1] Rundo, M. (2017) “Models for Flow Rate Simulation in Gear Pumps: A Review”, Energies, 10(9), 1261. DOI: 10.3390/en10091261.

[2] Gherardini, F., Zardin, B., Leali, F. (2016) "A parametric CAD-based method for modelling and simulation of positive displacement machines” J Mech Sci Technol 30(7): 3253-3263. DOI: 10.1007/s12206-016-0634-3.

[3] Frosina, E., Senatore, A., Buono, D. et Al. (2015) "Vane pump power split transmission: Three dimensional computational fluid dynamics modeling", ASME/BATH 2015 Symposium on Fluid Power and Motion Control, Chicago, USA, 12-14 October 2015. DOI: 10.1115/FPMC2015-9518.

[4] Frosina, E., Senatore, A., Rigosi, M. (2017) "Study of a high-pressure external gear pump with a computational fluid dynamic modeling approach", Energies, 10(8), 1113. DOI: 10.3390/en10081113.

[5] Borghi, M., Zardin, B. (2015) "Axial balance of external gear pumps and motors: Modelling and discussing the influence of elastohydrodynamic lubrication in the axial gap", ASME International Mechanical Engineering Congress and Exposition, Houston, USA 13-19 November 2015. DOI: 10.1115/IMECE2015-51632.

[6] Dhar, S., Vacca, A. (2013) "A fluid structure interaction - EHD model of the lubricating gaps in external gear machines: Formulation and validation”, Tribol. Int. 62: 78-90. DOI: 10.1016/j.triboint.2013.02.008.

[7] Rundo, M., Corvaglia, A. (2016) “Lumped parameters model of a crescent pump”, Energies 9(11). DOI: 10.3390/en9110876.

[8] Altare, G., Rundo, M. (2017) “Advances in simulation of gerotor pumps: An integrated approach”, Proc. IMechE Part C: J. Mechanical Engineering Science 231(7): 1221-1236. DOI: 10.1177/0954406217694663.

[9] Rundo, M., Altare, G. (2018) "Lumped Parameter and Three-Dimensional Computational Fluid Dynamics Simulation of a Variable Displacement Vane Pump for Engine Lubrication”, J. Fluids Eng. 140(6), 061101-1. DOI: 10.1115/1.4038761.

[10] Ivantysynova, M., Wieczorek, U. (2000) “CASPAR-a computer-aided design tool for axial piston machines", Bath Workshop on Power Transmission and Motion Control, Bath, United Kingdom.

[11] Roccatello, A., Mancò, S., Nervegna, N. (2007) "Modelling a Variable Displacement Axial Piston Pump in a Multibody Simulation Environment", J. Dyn. Syst., Meas., Control, 129(4): 456-468. DOI: 10.1115/1.2745851.

[12] Liu, G., Zhou, Z., Qian, X., Wu, X., Pang, W. (2016) “Multidisciplinary Design Optimization of a Swash-Plate Axial Piston Pump”, Appl. Sci. 6, 399. DOI: 10.3390/app6120399.

[13] Casoli, P., Vacca, A., Franzoni, G., Berta, G.L. (2006) "Modelling of fluid properties in hydraulic positive displacement machines", Simul. Model. Pract. Theory, 14(8): 1059-1072. DOI: 10.1016/j.simpat.2006.09.006.

[14] Kumar, S., Bergada, J.M., Watton, J. (2009) “Axial piston pump grooved slipper analysis by CFD simulation of three-dimensional NVS equation in cylindrical coordinates", Computers \& Fluids, 38: 648-663. DOI: 10.1016/j.compfluid.2008.06.007.

[15] Manring, N.D. (1999) "Friction Forces Within the Cylinder Bores of Swash-Plate Type Axial-Piston Pumps and Motors", J. Dyn. Sys., Meas., Control 121(3): 531-537. DOI: 10.1115/1.2802507.

[16] Macor, A., Rossetti A. (2011) “Optimization of hydro-mechanical power split transmissions”, Mech. Mach. Theory, 46(12): 1901-1919. DOI: 10.1016/j.mechmachtheory.2011.07.007.

[17] Casoli, P., Gambarotta, A., Pompini, N., Riccò, L. (2015) "Coupling excavator hydraulic system and internal combustion engine models for the real-time simulation", Control Engineering Practice, 41: 26-37. DOI: 10.1016/j.conengprac.2015.04.003.

[18] Nervegna, N., Mancò, S., Rundo, M. (2001) "Variable Flow Internal Gear Pump”, ASME International Mechanical Engineering Congress and Exposition, 11-16 November, New York, USA.

[19] Pellegri, M., Vacca, A., Frosina, E., Buono, D., Senatore, A. (2017) "Numerical analysis and experimental validation of Gerotor pumps: A comparison between a lumped parameter and a computational fluid dynamics-based approach", Proc. IMechE Part C: J. Mechanical Engineering Science 231(23): 4413-4430. DOI: 10.1177/0954406216666874.

[20] Gilardino, L., Mancò, S., Nervegna, N., Viotto F. (1999) “An experience in simulation: the case of a variable displacement axial piston pump”, 4th JHPS International Symposium on Fluid Power, Tokyo, Japan, 15-17 November, 1999. DOI: 10.5739/isfp.1999.85.

[21] Mancò, S., Nervegna, N., Lettini, A., Gilardino L. (2002) “Advances in the simulation of axial piston pumps", 5th JFPS International Symposium on Fluid Power, Nara, Japan, Nov. 12-15, 2002. DOI: 10.5739/isfp.2002.251.

[22] Borghi, M., Specchia, E., Zardin, B., Corradini, E. (2009) “The Critical Speed of Slipper Bearings in Axial Piston Swash Plate Type Pumps and Motors", ASME 2009 Dynamic Systems and Control Conference, Volume 1: 267-274. DOI: 10.1115/DSCC2009-2604.

[23] Schenk, A., Ivantysynova, M. (2015) “Transient Thermoelastohydrodynamic Lubrication Model for the Slipper/Swashplate in Axial Piston Machines", J. Tribol, 137(3), 031701. DOI: 10.1115/1.4029674.

[24] Ding, H., Visser, F. C., Jiang, Y., Furmanczyk, M. (2011) “Demonstration and Validation of a 3D CFD Simulation Tool Predicting Pump Performance and Cavitation for Industrial Applications”, ASME J. Fluids Eng., 133(1). DOI: 10.1115/1.4003196.

[25] Singhal, A.K., Athavale, M.H., Li, H., Jiang, Y. (2002) "Mathematical Basis and Validation of the Full Cavitation Model”, ASME J. Fluids Eng., 124: 617-624. DOI: 10.1115/1.1486223. 